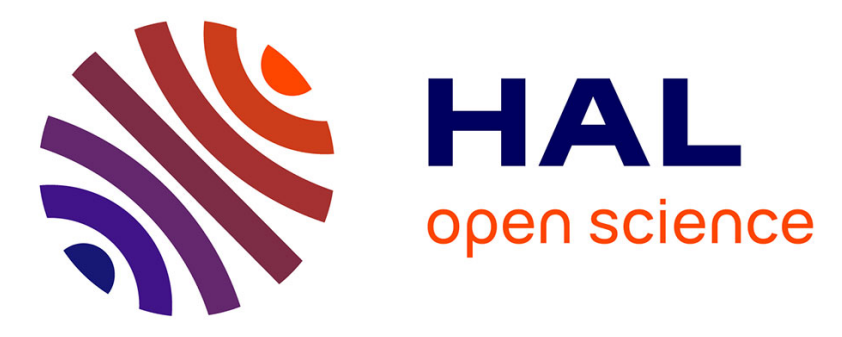

\title{
In-situ tensile tests under SEM and X-ray computed micro-tomography aimed at studying a self-healing matrix composite submitted to different thermomechanical cycles
}

Rémi Bertrand, Gerald Camus, Olivier Caty, Vincent Mazard, Sébastien Denneulin, Patrick Weisbecker, Jérôme Pailhes, Francis Rebillat

\section{To cite this version:}

Rémi Bertrand, Gerald Camus, Olivier Caty, Vincent Mazard, Sébastien Denneulin, et al.. In-situ tensile tests under SEM and X-ray computed micro-tomography aimed at studying a self-healing matrix composite submitted to different thermomechanical cycles. Journal of the European Ceramic Society, 2017, 37 (10), pp.3471-3474. 10.1016/j.jeurceramsoc.2017.03.067 . hal-02301760

\author{
HAL Id: hal-02301760 \\ https://hal.science/hal-02301760
}

Submitted on 30 Sep 2019

HAL is a multi-disciplinary open access archive for the deposit and dissemination of scientific research documents, whether they are published or not. The documents may come from teaching and research institutions in France or abroad, or from public or private research centers.
L'archive ouverte pluridisciplinaire HAL, est destinée au dépôt et à la diffusion de documents scientifiques de niveau recherche, publiés ou non, émanant des établissements d'enseignement et de recherche français ou étrangers, des laboratoires publics ou privés. 


\section{In-situ tensile tests under SEM and $X$-Ray computed micro- tomography for the study of the composite with self-healing matrix under different thermomechanical cycles}

\author{
Rémi BERTRAND ${ }^{1,2}$, Gerald CAMUS ${ }^{1}$, Olivier \\ CATY $^{1}$, Vincent MAZARS ${ }^{1,2}$, Sébastien \\ DENNEULIN $^{2}$, Patrick WEISBECKER ${ }^{1 \dagger}$, \\ Jérôme Pailhes $^{3}$, Francis REBILLAT ${ }^{1}$ \\ ${ }^{1}$ Laboratoire des Composites Thermostructuraux, \\ University of Bordeaux \& CNRS - CEA - SAFRAN \\ Herakles, 3 allée de la Boetie, 33600 Pessac, \\ France \\ ${ }^{2}$ SAFRAN Ceramics, rue de Touban Les 5 chemins, \\ 33185 Le Haillan, France \\ ${ }^{3} I 2 \mathrm{M}$, Institut de mécanique et d'ingénierie, \\ University of Bordeaux, 16 Avenue Pey Berland, \\ 33607 PESSAC, France \\ remi.bertrand@1cts.u-bordeaux.fr, camus@1cts.u-bordeaux.fr, \\ rebillat@1cts.u-bordeaux.fr, caty@1cts.u-bordeaux.fr, \\ mazars@ @ lcts.u-bordeaux.fr, jerome.pailhes@ensam.eu, \\ sebastien.denneulin@safrangroup.com
}

\begin{abstract}
Composites made of Ceramic for both fibres and matrix are three dimensional (3D) structured materials aimed at being used in aerospace applications. Material is submitted to mechanical stresses at high temperatures in oxidizing and corrosive environments for long durations. During thermomechanical cycles, damage, oxidation and healing-phenomenon appear and develop in the material. X-Ray Computed Micro-Tomography $(\mu \mathrm{CT})$ and tensile test under Scanning Electron Microscopy (SEM) are solutions which allow an experimental study of these phenomenons. These techniques are performed for the study of the behaviour of the oxide (solid or liquid) in the crack of the material. The influence of the state of the oxide in the crack was analysed during tensile test under SEM or $\mu \mathrm{CT}$. The observation of the crack shape allows to determine the influence of the oxide on the reclosure of the crack during the unloading.
\end{abstract}

Keywords: Tomography, in-situ tensile tests, oxidation, Ceramic matrix composites, Self-healing behaviour,

\section{Introduction}

The field of civil aeronautics seeks for replacing some of the structural components made of metallic alloys present in the engines [1-2]. During their use, these parts undergo high temperatures and relatively high stresses, under oxidizing and corrosive environments. SiC/SiBC composite with their fair resistance to high temperatures and excellent mechanical properties are candidates for such applications. However, when the applied stress is sufficiently high, a crack network is created within the material. Each of these microcracks is paths of oxygen to the carbon interphase and the $\mathrm{SiC}$ fibre. Oxidation of the interphase (which is essential to avoid a brittle behaviour) and of the fibre drastically reduces the lifetime of the material since $400^{\circ} \mathrm{C}$ [3]. Different types of matrices have been developed to limit oxidation of the interphase [4-5-6-7]. A matrix that combines carbides (deposited by CVI) has thus been especially developed with specific sequences of $\mathrm{Si}, \mathrm{C}, \mathrm{B}$ which generate protective oxides for a wide range of temperature [7-8]. In particular, boron oxide exhibits a low melting point (almost $460^{\circ} \mathrm{C}$ ), and an appropriate viscosity which can fill up matrix cracks at low temperature (almost $600^{\circ} \mathrm{C}$ ) [9]. This matrix can be used to protect the material from room temperature at high temperature because as soon as $450^{\circ} \mathrm{C}$ the layers with boron oxidize create self-healing glass.

Previous studies have showed that this selfhealing glass can modify the behaviour of the material according to the thermomechanical cycle endure by the composite [10]. Indeed, the solid oxide presents in the crack involves a stiffening phenomenon and can, in some cases, prevent the reclosure of the crack during the unloading. Micro computed tomography $(\mu \mathrm{CT})$ and tensile tests under SEM give the possibility of 3D image and analyse in-situ the material at different resolutions while loading it mechanically and thermally. These analyses give access to a very precise insight of behaviour of the oxide in the cracks [11-12]. This technique is used here for the in-situ study of damage at different stress states and at different temperatures up to $800^{\circ} \mathrm{C}$ on small samples.

\section{Material and methods}

\section{1) Material}

The SEM tensile tests are performed on a microtest tensile stage (Deben Microtest). This tensile stage is has a $1 \mathrm{kN}$ load cell and tensile speeds are in the range of $0.02 \mathrm{~mm} \cdot \mathrm{min}^{-1}$ to 0.4 $\mathrm{mm} \cdot \mathrm{min}^{-1}$. The material tested is a mini-composite composed of about 500 unidirectional $\mathrm{SiC}$ fibres (Hi-Nicalon fibres). In order to improve the protection of the SiC-Hi-Nicalon fibres, $50 \mu \mathrm{m}$ of matrix of [Si-B-C] is deposed by chemical vapour deposition. 
A special tension device (Fig. 1) was developed for in-situ tension tests in $\mu \mathrm{CT}$ scanners. This device is adapted for the GE-VTomx $\mu \mathrm{CT}$ and most of the synchrotron beam lines. The design was inspired from the one developed at INSA de Lyon [13] adapted for small $\mu \mathrm{CT}$ scanners using a hydraulic actuator and a joule effect heater. The device is designed for small specimen with a section up to $5 \times 5 \mathrm{~mm}^{2}$ and an utile length of $30 \mathrm{~mm}$ max. In this paper the utile length of the sample is $2.5 \times 2.5 \times 10 \mathrm{~mm}^{3}$ to fully image this section at a resolution of $7 \mu \mathrm{m}$. The maximum load is $5000 \mathrm{~N}$ and the maximum temperature available with this specimen and the power supply used $(16 \mathrm{~V} / 16 \mathrm{~A})$ is $1250^{\circ} \mathrm{C}$. The device is cooled by air, the temperature is measured by a pyrometer and the temperature is stable $(+/-1 \%)$ in the utile length of the sample.

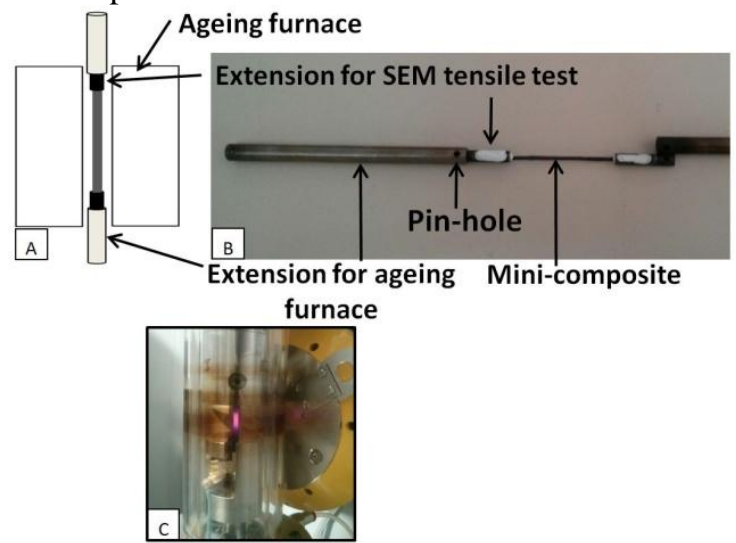

Figure 1 : (A) Schematic representation of the ageing furnace (B) Extension for the ageing furnace and the SEM tensile test, (C) Picture of the tension device in the $\mathrm{GE} / \mathrm{VTomx} \mu \mathrm{CT}$ with a specimen heated at $1000^{\circ} \mathrm{C}$

\section{2) SEM and $\mu C T$ tensile tests}

Before SEM tensile test, each sample is damaged and oxidized in an ageing furnace (Fig. 2). This method allows to control the cooling and the unloading. After this, the sample is placed on the tensile stage in the SEM. The tensile test is performed at room temperature and environmental SEM atmosphere. During the test, the evolution of a crack is observed by SEM to follow the solid oxide in the crack when the load is applied. Extensions were designed to be plugged in the ageing furnace and to hold SEM extensions for tensile tests (Fig. 2). These extensions are unmounted by removing the pin.

Tests were designed to analyse healing and in particular crack blockages due to the presence or not of solid oxide in the crack (depending on the type of cooling after or before the unloading). The test sequence is described on the Fig. 3. Initially, the sample is scanned without load at room temperature (scan I). Then the load is applied to create microcracks in the material (scan II). While the load is maintained, the temperature is increased to oxidize and heal the material $\left(800^{\circ} \mathrm{C}\right)$. After the cooling under load, the material is imaged maintaining the load (scan III). Before scan IV, load is removed to analyse crack blockages. Cracks are reopened (scan $\mathrm{V}$ ) and the temperature is increased to $800^{\circ} \mathrm{C}$ to liquefy oxide. Then, the load is removed before temperature to analyse the reclosing of the microcracks when the oxide is liquid (scan VI). Finally, scan VII is performed with load to observe effect of this expulsion on failure morphology (scan VII). Stress was $150 \mathrm{MPa}$ to damage the material without global failure. The temperature is raised to $800^{\circ} \mathrm{C}$ to liquefy the oxide without reaching the creep temperature of the $\mathrm{SiC}$ phases.

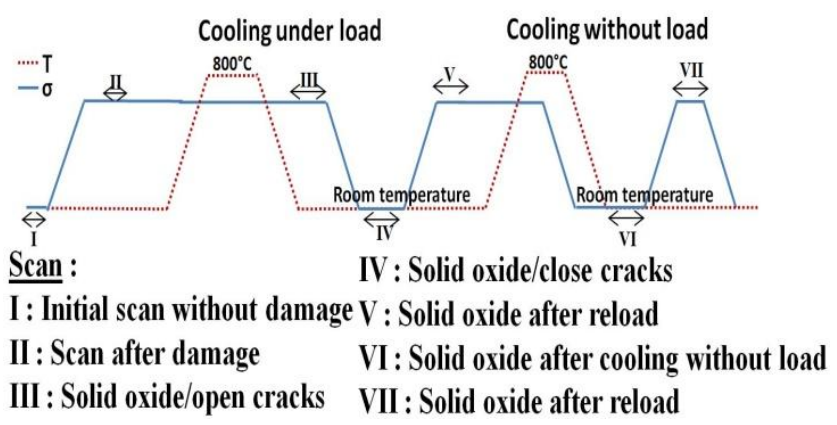

Figure 2 : Schematic description of in-situ tension tests at high temperature carried out to study the damage and healing of the material

\section{3. $\underline{\text { Results }}$}

\section{1) SEM tensile tests}

After the ageing of the sample, it is possible to decrease the temperature before the load. In this case, the solid oxide present in the crack blocks the closure of the crack. When the load is applied under SEM, a failure appears between a side of the crack and the solid healing oxide (highlighted by arrows on figure 3-A).

In the other case, if the cooling is done after the unloading, the liquid healing oxide is ejected out of the microcrack. This is highlighted by an arrow on figure 3.B. The liquid oxide at $800^{\circ} \mathrm{C}$ has a perfect wettability and it can coat the composite as soon as it is ejected out of the crack. When the load is again applied, some microcracks appear in the solid oxide layer present in the crack (see arrows on the Fig. 3.C). 


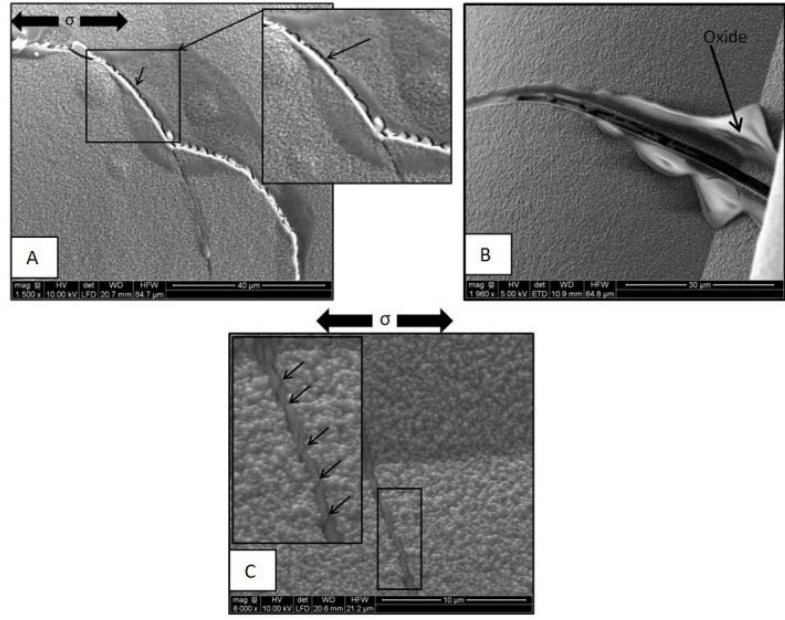

Figure 3 : (A) Illustration of the failure of the healing oxide phase, after cooling under load and tensile test under SEM (B) Liquid oxide partially ejected of the microcrack during the unloading at high temperature (C) microcracks in the solid oxide layer after loading, SEM micrographs

\section{2) $\mu \mathrm{CT}$ tensile test}

The Fig. 4-A presents the evolution of a crack in the sample for 7 loading steps. Initially (step 1, $0 \mathrm{~N})$, no crack is present in the material. Scan 2 is acquired after loading the material without temperature. A crack appears highlighted by the arrow. This crack evolves during the oxidation phase (step 3). After the first thermomechanical cycle (i.e. cooling under load), the crack is always opened whereas there is no load during the scan (step 4). Illustrating the blockage of the crack by the healing oxide at room temperature. When the load is applied again no difference are visible (step 5 ). On the contrary, when the load is removed before cooling, the crack is almost totally closed oxide not visible at this resolution on $\mu \mathrm{CT}$ (step 6). The crack is reopened when the load is applied again (step 7). Illustrating the blockage of the oxide as seen on figure 3 .

Fig. 4-B presents a 3D reconstruction of the material and the propagation of the crack already presented in the figure 6 . The green segmentation is the crack propagation during the step 5 (i.e. when the load is maintained). On the contrary, the blue segmentation is the crack during the step 6 (i.e. when the load is removed before cooling). The green segmentation is more developed than the blue. This is consistent with the better reclosure of the crack when the material is unloading before cooling (step 6). The volume of the crack is given in the table Fig 4-C. The volume of the crack to step 4 is almost the same as step 3 and 5. This is consistent with the fact that the material is unloading. However, this volume is still larger than that obtained in step 6 .
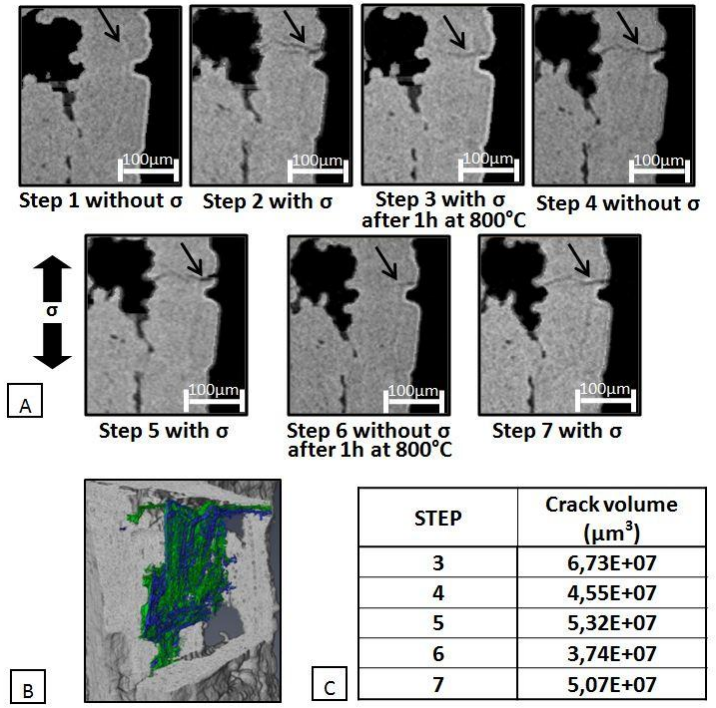

Figure 4 : (A) Seven states of the thermomechanical sequence describe in figure 3 . A zone of the working portion of the sample. The loading direction is indicated by hold arrow and $\sigma$. All acquisition was done at $20^{\circ} \mathrm{C}$ (B) Two crack segmentations (green after step 5 and blue after step 6). 3D reconstruction of the material after X-Ray computed micro-tomography (C) Volume of the crack as function of the step.

\section{Discussion}

The SEM analyzes were conducted for their accuracy (magnification factor x6000, Fig. 5-B) although on a localized area of a material model (mini-composite). The study by $\mu \mathrm{CT}$ gave comprehensive information on real composites at lower resolutions $(7 \mu \mathrm{m})$. In this paper, to obtain more information on the thermo-mechanical behaviour of the material, SEM and $\mu \mathrm{CT}$ were combined and run with in-situ tensile tests.

Thanks to tensile tests under SEM, it is possible to observe that, according to the type of cycle (cooling after or before the unloading), the material has not the same behaviour when a load is applied again:

- The first behaviour is when the cooling occurs before the unloading. As soon as a new load is applied the new crack occurs between solid oxide layer and the edge of the crack (Fig. 3-A). No new microcracks appear in the solid oxide. The interfacial bond between the oxide and the matrix is a weakness element. There is no acoustic emission and stiffening is lower which is explained by an oxide interface / low crack [10].

- In the other hand, when the unloading occurs before the cooling, as seen Fig. 3- 
$\mathrm{B}$, a part of the liquid healing oxide is ejected out of the crack. Then, after cooling, if the load is applied, multicracking occurs in the oxide layer (Fig. 3C). In this case, the interfacial bond between matrix and solid oxide seems more important that in the case where the cooling occurs under load. To reopen the crack, it is necessary to break the thin solid oxide layer.

The $\mu \mathrm{CT}$ tensile test, analyses in $3 \mathrm{D}$ the influence of healing solid oxide on the opening/closing of the crack when the material is unloading throughout composite sample. The solid healing oxide in the crack blocks the reclosure of the crack when the material is cooling under load (step 4 Fig.4-A). After the inverse cycle, i.e. unloading at high temperature, liquid healing oxide cannot prevent the reclosure of the crack. There is a thin layer of oxide which cracks when the load is applied again. This is supported by the previous tests that show the cracking of the oxide layer (Fig. 3-C). This behavior is accompanied by a stiffening of the material with an emission acoustic which reflects a multiple cracking oxide (Fig. 3-C). This phenomenon is studied in [10].

These different in-situ methods of characterization allow us to understand better the behavior of material. The observations and results are qualitative analyse although it is possible to quantify the crack opening during the tensile under SEM $(\approx 1.8 \pm 0.1 \mu \mathrm{m}$ on the Fig $3-\mathrm{B})$. The volume of the crack quantified by post treatment segmentation highlights the phenomenon of blockage. Indeed, without load, the crack during step 4 as almost the same volume that step 3 or 5 with load. Moreover, the reclosure of the crack is better when the oxide is liquid because the volume of the crack is smaller than in the other case (step 4, Fig. 4-C).

\section{Conclusion}

SEM tensile test and 3D $\mu \mathrm{CT}$ images are used to analyse and visualize crack initiation and propagation in self healing 3D CMC. These analyses were made in-situ using a high temperature tension device specially developed for this material and for SEM and $\mu$ CT. Two types of tests were carried out. The first allows to observe the influence of the type of cooling (before or after the unloading) on the mechanical behaviour when the solid oxide is present in the microcrack. Depending to the type of cooling, the solid oxide does not crack the same way: (i) if the stress is released after solidification: blocking of the crack, and there is failure along the interface healing oxide / material during the next reloading, (ii) if the material is unloading before solidification: crack closes, and the oxide is ejected. During the next reloading, the rest of oxides will crack and the mechanical behaviour will be degraded. The second test allows to bring to light the behaviour of healing phases submitted to load and temperature. Images presented were treated to better analyse cracks and phases. The cracks are rather straight and perpendicular of the load but located on a side of the sample. At high temperature the healing oxide were also observed and can prevent the reclosure of the crack when the material is cooling under load or be ejected in the other case.

\section{Acknowledgements}

This work has been supported by the Centre National de la Recherche Scientifique (CNRS) and Safran Ceramics (SAFRAN GROUP). The authors are grateful to Safran Ceramics for supplying the samples and to Felicien Auguin, Matias Gosset, Bruno Vicin and Jonathan Jouveau for their work during an internship on the development of the device and the in-situ tensile test and the I2M laboratory for the development of the device in particular and Fabrice Prince and Jean Marie Diaz.

\section{$\underline{\text { References }}$}

[1] R. Naslain, A. Guette, F. Rebillat, R. Pailler, F. Langlais, X. Bourrat "Boron-bearing species in ceramic matrix composites for long-term aerospace applications" Journal of solid State Chemistry, 177, Issue 2, (2004), $\quad$ pp. 449-456 doi:10.1016/i.jssc.2003.03.005

[2] G. Habarou, P. Spriet "Applications of CMCs to Turbojet Engines: Overview of the SEP Experience" Key Engineering Materials, Vols. 127-131, (1997), pp. 1267-1276

[3] L. Filipuzzi, R. Naslain, A. Guette, F. Rebillat, S. Le Gallet, F. Lamouroux, C. Louchet "Oxidation mechanisms and kinetics of $\mathrm{SiC}$-matrix composites and their constituents" Journal of materials science, 39, (2004), pp. 7303-7316

[4] S. Goujard, L. Vandenbulcke et H. Tawil "Oxydation behaviour of $2 \mathrm{D}$ and $3 \mathrm{D} \mathrm{C/SiC}$ thermostructural materials protected by CVD polylayers coatings" Thin Solid Films, 252, (1994), pp. 120-130, doi:10.1016/00406090(94)90783-8

[5] S.M. Gee, J.A. Little "Oxidation behaviour and protection of carbon composites" Journal of materials science, 16, (1991), pp. 1093-1100, doi:10.1007/BF00576792

[6] H. Dietrich "Carbon/carbon protected/protected" Materials engineering, 108, $\mathrm{n}^{\circ} 8,(1991)$, pp. 34-35

[7] R.M. Buchanan, F.E. Henn, N. Jiang et D.A. Stevenson "Permittivity and AC conductivity in Yttria-stabilised zirconia" Applied Physics, 60, Issue 5, (1995), pp. 515-519, doi: 10.1007/BF01538778

[8] L. Baroumes, E. Bouillon, F. Christin "An Improved Long Life Duration CMC for Jet Aircraft Engine Applications" ICAS $24^{\mathrm{TH}}$ INTERNATIONAL 
CONGRESS OF THE AERONAUTICAL SCIENCES, (2004)

[9] F.J. Buchanan, J.A. Little "Glass sealants for carbon-carbon composites" Journal of materials science, 28, (1993), pp. 2324-2330

[10] R. Bertrand, G. Camus, F. Rebillat "Influence of thermomechanical cycling on the behaviour of a selfhealing Ceramic Matrix Composite in an oxidizing atmosphere" under review

[11] H. Bale, A. Haboub, A.A. MacDowell, J.R Naiatka, D.Y. Parkinson, B.N. Cox, D.B. Marshall, R.O. Ritchie. "Real-time quantitative imaging of failure events in materials under load at temperatures above $1600^{\circ} \mathrm{C}$ " Nature Materials, 12, (2013), pp. 40-46, doi:10.1038/nmat3497

[12] O. Caty, P. Ibarroule, M. Herbreteau, F. Rebillat, E. Maire, G.L. Vignoles "Application of X-Ray computed micro-tomography to the study of damage and oxidation kinetics of thermostructural composites" Nuclear instruments and methods in physics research B, 324, (2014), pp. 113-117.

[13] L. Salvo, P. Cloetens, E. Maire, S. Zabler, J.J. Blandin, J.Y. Buffière, W. Ludwig, E. Boller, D. Bellet, C. Josserond "X-ray micro-tomography an attractive characterisation technique in materials science" Nuclear Instruments and Methods in Physics Research Section B: Beam Interactions with Materials and Atoms, 200, (2003), pp. 273-286. 